\title{
Incidence of Mycotoxin-Producing Fungi in Overripe Fruits Sold in Lugbe Market and Its Potential Health Implications
}

\author{
G. B. Olukotun", R. R. Ideh, N. O. Oyedokun, T. Abdulkareem, O. J. Asake, O. A. Onuh \\ Product Development Unit, BED, National Biotechnology Development Agency, (FMST), Umaru MusaYar’adua Expressway, \\ Abuja, Nigeria.
}

\begin{abstract}
How to cite this paper: G. B. Olukotun, R. R. Ideh, N. O. Oyedokun, T. Abdulkareem, O. J. Asake, O. A. Onuh. (2021) Incidence of Mycotoxin-Producing Fungi in Overripe Fruits Sold in Lugbe Market and Its Potential Health Implications. International Journal of Food Science and Agriculture, 5(3), 381-388.

DOI: 10.26855/ijfsa.2021.09.007
\end{abstract}

Received: May 31, 2021

Accepted: June 27, 2021

Published: July 22, 2021

*Corresponding author: G. B. Olukotun, Product Development Unit, BED, National Biotechnology Development Agency, (FMST), Umaru MusaYar'adua Expressway, Abuja, Nigeria.

Email: Debotun714@gmail.com

\begin{abstract}
Many strains of fungi are known to produce mycotoxins, especially aflatoxin, ochratoxin A, patulin and alternaria toxins which are secondary metabolites released into foods and food products. The incidence of these metabolites in foods especially fruits is of great human health concern due to its toxigenic potentials even at low dose levels. Of greater concerns is the consumers' attitude toward the consumption of these fruits, particularly in the areas we studied. The major aim of this research was therefore, to determine the prevalence of fungi associated with ripe, over-ripe and rotten fruits and the consumers' responses using structured questionnaire as well as empirical laboratory analysis. The fungal analysis of the vended ripe and overripe fruits was studied using standard analytical methods. Results show that fungi isolated from the fruits were Aspergillus niger, which is a potent producer of mycotoxin (37\%), Fusarium sp. (8\%), Mucor mucedo (18\%), Aspergillus fumigatus (13\%), Mucor sp. (11\%), Aspergillus flavus (5\%), Penicillium digitatum (4\%), Rhizopus stolonifer (3\%) and Phytophthora sp. (2\%) in that order. This indicates that these fungi species are of economic and public health significance as they are capable of producing toxic compounds in fruits. The toxic substances can result to food poisoning or intoxication if consumed. High poverty level and lack of awareness that over-ripe fruits provide good ground for the growth and production of toxin-laden fungi are the leading factors responsible for many people eating overripe fruits according to our questionnaire. The questionnaire analyses also show that many people are unaware of the dangers associated with the consumption of over-ripe fruits. The results of this work could be used as added material for educating the masses about the dangers of consuming toxigenic materials especially unwholesome fruits.
\end{abstract}

\section{Keywords}

Mycotoxin, Fungi, Over-ripe fruit, Aspergillus niger, Human health, Consumption

\section{Introduction}

Food safety issue is of little challenge in advanced countries today, owing to adequate advocacy on human mycotoxicosis. However, there still exist notable outbreaks in the developing countries. Fungal contaminations have been noted for years. It has been widely suggested that the Bible tenth plaque could be attributed to trichothecene mycotoxins and that the thousands of deaths in Europe, in the middle ages, caused by the St. Anthony's fire (today recognized as ergotism) could be produced by the ingestion of the ergots of Claviceps purpurea, which is a fungus occurring on some grains.

Aflatoxins were confirmed in 1961, being named by the species of fungus that had been first described (Aspergillus 
flavus toxin). However, world-wide recognition of mycotoxin problem was reported in 1960 when about 100,000 turkey pouts died in England as a result of consumption of feeds contaminated by the toxin [1].

The severity of mycotoxin problem was realized during World War II when Russians were eating moldy winter grains, they suffered severe dermal necrosis, leucopenia, hemorrhages and destruction of bone marrow, Fusarium was found to be the causal organism of these abnormalities which emerged after World War II [2].

Aflatoxins are metabolites of closely related properties produced by Aspergillus flavus, Aspergillus parasiticus among others. Mycotoxins such as aflatoxin and tenuazonic acid are also produced by Alternaria fungi which are parasites of plants and may cause spoilage of fruits and vegetables during transport, storage or sale. These secondary metabolites have deleterious biological effects in animal and humans [3].

Most advanced countries have certain tolerable maximum levels of aflatoxins in foods beyond which such foods are not permitted in circulation in order to protect human health. Large populations of these countries are familiar with the likelihood of food poisoning due to aflatoxin consumption in their food chain. Unfortunately, in developing countries like Nigeria, several people are not aware of the dangers associated with consumption of fungi-laden fruits and foods.

Monitoring and regulatory activities for aflatoxin requires state-of-the-art analytical procedures which are often not available in poor countries. Also, rapid and effective screenings of aflatoxin-producing fungi are grossly insufficient in the developing countries. In order to avert the problems of mycotoxin ingestion in foods, it is better to adopt preventive methods which include understanding the prevalence and rout of the possible causal agents of mycotoxins in order to be able to proffer effective education and stand points for their control.

The major aim of this paper was therefore to empirically analyze the incidence of fungal association with overripe and rotting fruits sold in Lugbe market and to understudy the fruit consumer behaviors towards the consumption of these unwholesome materials with the aim to advancing cautionary measures in the locality, Nigeria and beyond.

\section{Materials and Methods}

\subsection{Sample Collection}

Overripe, ripped and spoilt fruit samples (orange, banana, pawpaw, pineapple, water melon, tomato, onions, ginger, eggplant and pears) were randomly collected from retail sellers in Lugbe market, FCT, Abuja, Nigeria. Of the 200 samples collected, 160 fruits had lesion (defects, blemishes, and decays found on fresh fruits and vegetables) at the commercial and consumer level which are often time symptom of microbial colonization. Twenty (20) spoilt fruits and 20 healthy ones (control) were collected and analysed from December, 2018 to April, 2019. The samples were placed in a sterile plastic bag and labeled prior to analysis. The spoilt fruits were identified by morphological examination using the method of Gultie et al. [4]. The samples were kept in the refrigerator at $4^{\circ} \mathrm{C}$ for further laboratory analysis.

\subsection{Culture Media Preparation}

Potato Dextrose Agar (PDA) containing chloramphenicol (30 $\mathrm{mg} \mathrm{mL}^{-1}$ ) was used. The culture media were prepared according to manufacturer's recommendations. The quantities of the appropriate medium were weighed followed by suspending the weighed amount of the media in $400 \mathrm{~mL}$ of distilled water. The media were heated to boil over Bunsen flame until the agar melted. The molten agar media were allowed to cool to $45^{\circ} \mathrm{C}$ and the $\mathrm{pH}$ adjusted according to the manufacturer's recommendation. The media were cotton plugged and wrapped with aluminum foil and were autoclaved at $121^{\circ} \mathrm{C}$ at a pressure of $110 \mathrm{kPa}$ for $15 \mathrm{~min}$. After sterilization, the media were aseptically dispensed in $20 \mathrm{~mL}$ aliquots sterile Petri dishes and were allowed to set on the flat platform. The Petri dishes were labeled appropriately for later use.

\subsection{Isolation of fungi from spoilt fruits}

Following the method of Gultie et al. [4], the lesion fruits were surface sterilized with cotton wool soaked in $70 \%$ ethanol for 2 min then rinsed 3 times with distilled water. A sterile blade and forceps was used to cut small section of the tissue containing both the healthy and the rotten portion ( $3 \mathrm{~mm}$ diameter) and plated on solidified Potato Dextrose Agar (PDA) containing chloramphenicol $\left(30 \mathrm{mg} \mathrm{mL}^{-1}\right)$ to prevent bacterial growth. The inoculated plates were incubated at ambient temperature $\left(25^{\circ} \mathrm{C}\right)$ for 7 days. Various colonies observed in the plates were distinguished on the basis of their cultural characteristics such as colony size, shape, colour and consistency characteristics. The pure fungal isolates were sub-cultured on to PDA slants to obtain pure isolates.

\subsection{Identification of Fungal Isolates}

All the fungal isolates obtained from the slant were identified based on their gross morphology such as colony growth pattern, conidial morphology and pigmentation by slide culture techniques according to standard methods. A small portion of the aerial mycelia from the representative culture was picked using a sterile inoculating needle and inoculated on a slide containing a fraction of a prepared solidified Potato Dextrose Agar and incubated for $48 \mathrm{~h}$, after which it was 
viewed under the light microscope first with low resolution objective of x10 and then with high resolution objective of x40 to detect spore, hyphae and other special structures according to the methods described by Oyeleke et al. [5] and Thiyam and Sharma [6]. The morphological characteristics and appearance of the fungal isolates from the rotten fruits used in this study were confirmed and authenticated with the help of mycological atlas [7]. A total of 150 pure fungal isolates were identified.

\subsection{Assay for the Pathogenicity of Fungal Isolates}

Pathogenicity assay was carried out to know if the isolated fungi were really responsible for the spoilage of the fruits. Three healthy fruits from each sample were surface sterilized with $70 \%$ ethanol, and incisions were made on them using a sterile $4 \mathrm{~mm}$ cork borer; similar sterile cork-borer was used to cut pellets of agar containing the cultures of fungal mycelia of the isolates. These fungi were then inoculated into the hole created on the healthy fruits in a laminar flow chamber. The inoculated wound was sealed with petroleum jelly. Two controls with incision but not inoculated were established. The inoculated fruits and the controls were placed in a clean polyethene bag (one fruit per bag) each moistened with wet balls of absorbent cotton wool to create a humid environment and were incubated at $28^{0} \mathrm{C}$ for $72 \mathrm{~h}$, after which the inoculated fruits were observed for symptom development. The causal agents were re-isolated from the infected fruits and compared with the original isolates.

\section{Results}

Table 1 shows the Macroscopic and Microscopic Characterization of Fungal Isolates from Overripe/Spoilt Fruits Sold in Lugbe Market, FCT, Abuja. The result shows that five fungal species, Aspergillus sp, Rhizopus sp, Fusarium sp, Phytophora sp, Penicillium sp and Mucor sp. were identified from the pool of 150 pure isolates gotten from the ten fruits. Aspergillus niger was isolated from eight fruits, representing 55 isolates out of the total of 150 pure isolates, thereby recording the highest occurrence (37\%), while Phytophthora sp was isolated from two of the fruits (3 isolates) recording 2\% occurrence. The occurrence and distribution of fungi on the fruits are shown in Table 2.

The pathogenicity tests revealed that the isolated organisms were pathogenic. They were able to produce the same spoilage signs in the healthy fruits into which they were re-inoculated (Plate A). Table 3 shows the diameter of decay produced by each isolates on the eighteenth day of inoculation and incubation.

Table 1. Macroscopic and Microscopic Characterization of Fungal Isolates from Over-Ripe/Spoilt Fruits Sold in Lugbe Market, FCT, Abuja

\begin{tabular}{|c|c|c|}
\hline Macroscopic morphology & Microscopic morphology & Isolate \\
\hline $\begin{array}{l}\text { Rapid to moderately rapid growth rates. Initially whitish } \\
\text { colony but turns dense carbon black }\end{array}$ & $\begin{array}{l}\text { Fairly thick, septate hyphae } \\
\text { There is a chain of conidia on the sterimata. }\end{array}$ & Aspergillus niger \\
\hline $\begin{array}{l}\text { It grows rapidly, quickly covers the surface of the agar. } \\
\text { It's fluffy white cottony appearance becoming grayish } \\
\text { brown in time. }\end{array}$ & $\begin{array}{l}\text { Thick, wooly non septate hyphae with some dark } \\
\text { conidiospores. }\end{array}$ & Mucor mucedo \\
\hline $\begin{array}{l}\text { Bluish-green to gray colony color. Older culture is smoky } \\
\text { gray-green with a slight yellow reverse }\end{array}$ & $\begin{array}{l}\text { Hyphae are septate and hyaline. Conidial heads } \\
\text { are strongly columnar, smooth to finely roughen. }\end{array}$ & $\begin{array}{l}\text { Aspergillus fu- } \\
\text { migatus }\end{array}$ \\
\hline $\begin{array}{l}\text { White to pink colonies having few mycelium scattered } \\
\text { among the cottony looking mass. }\end{array}$ & $\begin{array}{l}\text { Ovoidal shaped conidia on phialides with septate } \\
\text { branching conidiospores }\end{array}$ & $\begin{array}{l}\text { Fusarium oxys- } \\
\quad \text { porum }\end{array}$ \\
\hline $\begin{array}{l}\text { Fluffy white appearance with a height of several } \mathrm{cm} \text { re- } \\
\text { sembles cotton candy }\end{array}$ & $\begin{array}{l}\text { Sporangiophores are short, erect, taper towards } \\
\text { their apices and form short sympodial branches }\end{array}$ & Mucor sp \\
\hline $\begin{array}{l}\text { Whitish foamy growth with gas } \\
\text { Bluish brown colouration with threadlike hyphae }\end{array}$ & Motile sporangia & Phythophthora sp \\
\hline $\begin{array}{l}\text { Rapid growth, woolly to cottony to somewhat granular, } \\
\text { olive to lime green with a cream reverse. }\end{array}$ & $\begin{array}{l}\text { Hyphae are septate and hyaline. Conidial heads } \\
\text { are radiate to loosely columnar with age. }\end{array}$ & $\begin{array}{l}\text { Aspergillus fla- } \\
\quad \text { vus }\end{array}$ \\
\hline $\begin{array}{l}\text { Woolly to cottony, white to cream colour, flat, spreading } \\
\text { colonies }\end{array}$ & $\begin{array}{l}\text { Ovoidal shaped conidia on phialides with septate } \\
\text { branching conidiospores }\end{array}$ & Fusarium sp \\
\hline $\begin{array}{l}\text { Very fast growing mass of fluffy slender mycelium with } \\
\text { black dot of conidiospore. } \\
\text { Initially white mass but become brown to black with age }\end{array}$ & $\begin{array}{l}\text { Non-septate mycelia with ovoidal sporangios- } \\
\text { phore }\end{array}$ & Rh. stolonifer \\
\hline Milky-white periphery, bluish-gray to green at the centre. & $\begin{array}{l}\text { Branching, green, brush-like spore-bearing } \\
\text { structures (penicillin) }\end{array}$ & Penicillium sp. \\
\hline
\end{tabular}


Table 2. Frequency of Occurrence of Fungal Isolates

\begin{tabular}{ccc}
\hline Fungal Isolates & Fruits infected & Frequency of Occurrence (\%) \\
\hline A. niger & Oranges, pineapples, bananas, pawpaw, pears, eggplant, ginger and onions & 37 \\
Fusarium sp & pineapples, pawpaw, bananas, ginger and pears & 8 \\
A. fumigatus & oranges, ginger, pineapples, bananas and pears & 13 \\
Mucor sp & tomato, watermelon, oranges and pears & 11 \\
A. flavus & tomato, watermelon, eggplant, oranges and pears & 5 \\
P. digitatum & oranges, ginger, pears, bananas and tomato & 4 \\
Rhizopus stolonifer & pawpaw, tomato, pears, eggplant and water melon & 3 \\
Phytophthora sp & onions and eggplant & 2 \\
\hline
\end{tabular}

Percentage Occurrence of Fungal

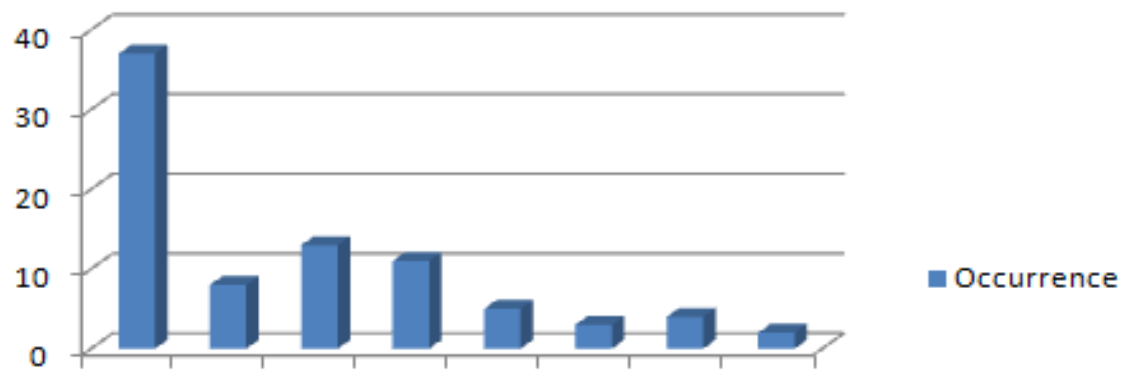

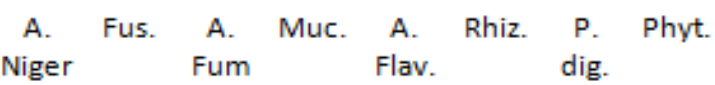

Fungal Isolates

Figure 1. Percentage of Fungal Occurrence in the Fruits.

Table 3. Decomposition profile of isolates at $18^{\text {th }}$ day of incubation (Koch's postulate)

\begin{tabular}{cc}
\hline Fungal Isolate & Diameter Infected \\
\hline A. niger & 48 \\
Fusarium spp. & 42 \\
A. fumigatus & 36 \\
Mucor sp. & 30 \\
A. flavus & 28 \\
P. digitatum & 23 \\
Rhizopus stolonifera & 40 \\
Phytophthora sp. & 34 \\
\hline
\end{tabular}

\section{Discussions}

Fungal association with fruit spoilage has been reported severally. The fungi found associated with the spoilage of the various fruits collected from Lugbe market in FCT, Abuja, Nigeria during the period of our research were Aspergillus niger, Aspergillus flavus, Aspergillus fumigatus, Penicillum sp., Fusarium sp., Rhizopus stolonifer and Phytophthora sp. A. niger had the highest frequency of occurrence (37\%), and was associated with eight of the ten fruits studied. Similarly, Mailafia et al. [8] found that A. niger had the highest occurrence in spoilt pineapple, watermelon, oranges, pawpaw, and tomatoes vended in Gwagwalada Market, Abuja, with a frequency of 38\%. In our study however, A. niger was not isolated from watermelon and tomato.

Baiyewu et al. [9] reported that Aspergillus sp. and Rhizopus sp, which is the same genus with those isolated in the course of this study, were responsible for the soft rots of Pawpaw in southwestern Nigeria. Penicillum sp., A. fumigatus, A. niger and Rhizopus were found associated with deterioration of orange in this study. This is in line with the work of 
Akinmusire [10] who reported that Aspergillus sp. is the predominant organism associated with the spoilage of orange. Similarly, in another study, Aspergillus niger, Rhizopus stolonifer, Mucor mucedo, Penicillium digitatum and Aspergillus flavus were reported to be associated with the post-harvest spoilage of sweet oranges sold in Awka major markets in Nigeria [11].

The isolation of Phytophthora Sp. and Aspergillus flavus from pineapple is in line with the work of Efiuvwevwere [12] who reported that Aspergillus sp. is responsible for rottening of pineapple. Likewise, species of Aspergillus, Fusarium, Rhizopus, Penicillium and Candida were associated with spoilage of pineapple sold in Awka Market [13]. The presence of Fusarium sp., Rhizopus stolonifer and Mucor Sp. on tomato confirmed the studies of Oluwakemi et al. [14] and Lamidi [15] who reported that Fusarium sp, and Rhizopus stolonifer are responsible for the soft rot of tomato.

The incidence of the isolated fungi in this study as the spoilage organism of fruits and vegetables could be due to farming operation or post-harvest handling [16]. For instance, damage inflicted on produce at the time of harvest is a major cause of infection since most of the spoilage microorganisms invade the produce through such damaged tissues according to our interview with the vendors. Similarly, the extent of deterioration is influenced by the depth of the wound [17]. Furthermore, the incidence of infection is worsened by poor sanitary practices as observed around the fruit sellers in the areas studied. This also includes cross-contamination, contact infection during the transportation of produce. Whatever the cause may be, their presence is of public health concern.

Fungi from genera Aspergillus, Penicillium, Fusarium, Rhizopus, Alternaria and others are frequently being reported as contaminants of cereals, cattle nutrients and other herb products used in animal and human nutrition [18]. The most significant mycotoxins; aflatoxin, zearalenone, ochratoxin, trichotecen, fumonisin and palutin are produced by some strains among these fungi [19]. Another concern is that they are thermo-stable and resistant to denaturating agent in the process of their control [20]. Among the fungi isolated in this study includes the causal agents of mycotoxicoses of acute or chronic course, affecting the central nervous system, lungs, liver, digestive or cardiovascular systems [18]. Their disorders are reported to manifest as poisoning, with special accent on their cumulative, carcinogenic, teratogenic and mycogenic effects [21].

The genus Aspergillus which has the highest occurrence among the overall isolates contain a number of economically significant, highly mycotoxigenic species [22]. The aflatoxigenic species is clearly the most important from the point of view of human health, although ochratoxin production by a number of Aspergillus species is becoming increasingly important. Many of the other mycotoxins produced by Aspergillus may have roles in cancer induction and immunosuppression, though these are yet to be elucidated.

The questionnaire analyses show that $78 \%$ of the population does not know the difference between ripe and over-ripe fruit in term of the health implications. Twenty-four percent (24\%) who knew, irrespective of their educational levels, felt the nutritional values outweigh the perceived dangers. About $64 \%$ of the population are neither aware nor care about the values of what they eat because according to them, they buy what they could financially afford.

\section{Recommendations}

From our studies, both in the laboratory analyses and from the questionnaire, we wish to suggest that:

- Farmers and traders should maintain contacts with retailers to be aware of market preferences so that they can arrange post-harvest handling practices to provide produce of the desired quality free from mycotoxins- producing agents;

- Government Agriculture Ministry should include commission agency whose role is to take produce owned by a farmer or a trader and sell it for the best price possible as well as under the best storage conditions to avoid the delay that often give room for fungal growth and mycotoxin build up;

- The wholesale market which provides a convenient point for the gathering of large amounts of fruit produce from many sources and for its division into small assortments to meet the needs of retailers should be saddled with the responsibility of ensuring appropriate storage and distribution conditions void of congestion, high temperature and humidity which are all predisposition for microbial growth and toxin liberation;

- Although hawking has been part of market systems for centuries, the practice should be discouraged because the fruits they hawk often are exposed to various adverse conditions suitable for fungal growth and its associated hazards;

- $\quad$ Supermarkets can and should negotiate directly with growers for supplies of fresh produce, thus eliminating middleman entirely thereby ensuring that produce are sold at best price and good conditions.

Post-harvest techniques that eliminate delay of fruit produce to distant markets can be greatly enhanced by the use of post-harvest technology. A wide range of techniques to delay ripening, to inhibit ageing and to control pests are now available and the knowledge should be communicated to both the farmers and the fruit sellers.

The use of market information system such as dissemination of advance breakthroughs made in scientific research from relevant sections of the fruit and vegetable industry will benefit all stockholders. For instance, storage agencies 
will be able to use their facilities more efficiently if they are more alert to market trends.

The lack of qualified personnel is a major constraint to market improvement in developing countries. A prerequisite of any marketing development programme should be the presence of people experienced in all aspects of fruit and vegetable marketing. Training could be done to assist farmers and post-harvest handlers on for instance; the management of storage facilities and packing houses. Traders and post-harvest handling groups will also need to be well informed of all the dangers associated with deterioration of fruits and vegetables.

Further studies are necessary to improve and expand a model for mycotoxin producing strains of fungi in Nigeria and their current health effects. In this way, similar studies at regional levels could be integrated into primary and secondary models in software using common databases. The impacts of various factors such as atmospheric composition, interactions between different fungi should be studied and documented.

\section{Conclusions}

Analysis of 150 samples of ripe and overripe fruits, randomly collected from daily sale in the last three months of 2018/19 proved the presence of fungi potentially important for mycotoxin production and liberation into fruits. Results of analyses of the questionnaire are quite worrisome because vast majority (78\%) of the populace are not aware of the danger inherent in the consumption of over-ripe fruits in the area studied. People's level of education did not matter in the premium placed on deteriorating fruits.

The study and the corresponding findings will contribute to more awareness of fungal growth on fruits and toxin production in the food chain.

\section{References}

[1] Smith, J. S., Williams, W. P., and Windham, G. L. (2019). Aflatoxin in maize: a review of the early literature from "moldy-corn toxicosis" to the genetics of aflatoxin accumulation resistance; Mycotoxin Research, volume 35, pp. 111-128.

[2] Koehler, P., Tacke, D., and Cornely, O. A. (2016). Bone and joint infections by Mucorales, Scedosporium, Fusarium and even rarer fungi. Crit Rev Microbiol, 42: 158-71.

[3] Logrieco, A., Moretti, A., and Solfrizzo, M. (2009). Alternaria toxins and plant diseases: an overview of origin, occurrence and risks. World Mycotoxin J., 2: 129-140.

[4] Gultie, A., Sahile, S., and Subramanian, C. (2013). Assessment of fruit management in Gondar town markets of North Western Ethiopia. GJBAHS, 2013, 2(4): 4-8.

[5] Oyeleke, A., Manga, S. B. (2008). Essential of Laboratory Practice. 3rd ed. Minna, Niger state, Nigeria: Tobest Publisher. Pp. $12-29$.

[6] Thiyam, B. and Sharma, G. D. (2013). Isolation and identification of fungi associated with local fruits of Barak Valley, Assam. Curr. World Environ, 2013, 8(2): 319-322.

[7] Domsch, K. H., W. Gams, and T. H. Anderson. (1993). Compendium of Soil Fungi. Academic Press, London. P. 860.

[8] Mailafia, S., Okoh, G. R., Olabode, H. O. K., Osanupin, R. (2017). Isolation and identification of fungi associated with spoilt fruits vended in Gwagwalada market, Abuja, Nigeria. Veterinary World, 10(4): 393-397.

[9] Baiyewu, R. A., N. A. Amusa, O. A. Ayoola, and O. O. Babalola. (2007). Survey of the post-harvest diseases and aflatoxin contamination of marketed pawpaw fruit (Carica papaya L.) in South Western Nigeria. Afr. J. Biotechnol., 6: 178-181.

[10] Akinmusire, O. O. (2011). Fungal Species associated with the spoilage of some edible fruits in Maiduguri, North Eastern Nigeria. Advances in Environmental Biology, 5(1): 157-161.

[11] Onuorah Samuel, Obika Ifeanyi, and Okafor Ugochukwu. (2015). Filamentous Fungi Associated with the Spoilage of Post-Harvest Sweet Orange Fruits (Citrus Sinensis) Sold in Awka Major Markets, Nigeria. Bioengineering and Bioscience, 3(3), 44-49

[12] Efiuvwere. (2000). Microbial spoilage agents of tropical and assorted fruits and vegetables. $1^{\text {st }}$ ed. Port Harcourt: Paragraphics Publishers.

[13] Onuorah, S., Udemezue, O., Uche, J., and Okoli, I. C. (2013). Fungi Associated with the Spoilage of Pineapple Fruits in Eke Awka Market Anambra State. The Bioscientist Journal, 1(1), 22-27.

[14] Oluwakemi, O. I., Ademola, E. A., and Anthony, T. I. (2020). A review on the consumption of vended fruits: microbial assessment, risk, and its control. Food Quality and Safety, Volume 4, Issue 2, May 2020, pp. 77-81.

[15] Lamidi, Y. and Olorunmowaju. (2020). Isolation and Identification of Fungi Associated With Tomato (Lycopersicon Esculentum M.). Journal of Agriculture and Veterinary Sciences, 3(5): 2617-3131.

[16] Gustavo, B. C. V., Juan, F. M. J. Stella, M. S. T. Maria, L. M. Aurelio, and W. C. Jorge. (2003). "Handling and preservation of fruits and vegetables by combined methods for rural areas,” Technical Manual FAO Agricultural Services Bulletin 149, FAO, Rome, Italy, 2003. 
[17] FAO. (2008). Basic Harvest and Post-Harvest Handling Considerations for Fresh Fruits and Vegetables handling and Preservation, FAO, Rome, Italy, 2008.

[18] Richardson, M. D., Richardson R. Aspergillus, and Aspergillosis. (2015). In: Paterson R. R. M., Lima N. (eds.), Molecular Biology of Food and Water Borne Mycotoxigenic and Mycotic Fungi. CRC Press; Boca Raton, FL, USA: 2015. Pp. 151-164.

[19] Brenier-Pinchart, M. P., Faure, O., Garban, F., Fricker-Hidalgo, H., Mallaret, M. R., Trens, A., Lebeau, B., Pelloux, H., Grillot R. (2006). Ten-year surveillance of fungal contamination of food within a protected haematological unit. Mycoses. 2006, 49: 421-425.

[20] Petzinger, E. and Weidenbach, A. (2002). Mycotoxins in the food chain: The role of ochratoxins. Livest. Prod. Sci., 2002, 76: 245-250.

[21] Paterson, R. R. M. and Lima, N. (2015). Molecular Biology of Food and Water Borne Mycotoxigenic and Mycotic Fungi. CRC Press; Boca Raton, FL, USA: 2015.

[22] Al-Hindi, R. R, Al-Najada, A. R., and Mohamed, S. A. (2011). Isolation and identification of some fruit spoilage fungi: Screening of plant cell wall degrading enzymes. Afr. J. Microbiol. Res., 2011, 5(4): 443-448.

PLATE A: Isolation of Fungi from Over-ripe Fruit Lesion

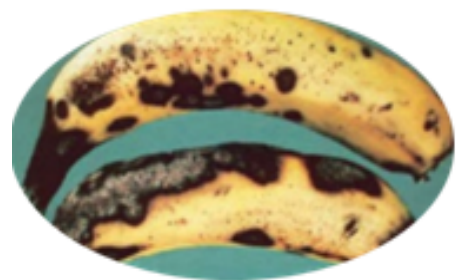

A

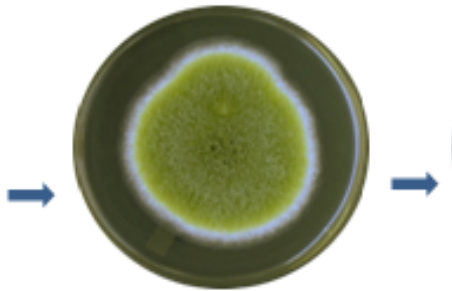

B

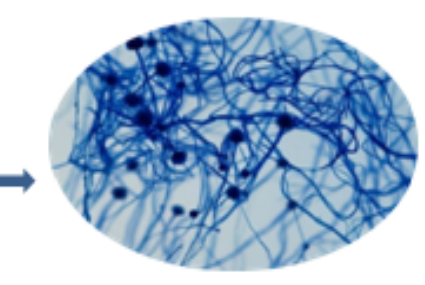

$\mathrm{C}$

Lesionson over-ripe banana (A), Culture of dominant Fungi from the lesion (B) and Microscopic view of the Fungi (C).

\section{PLATE B: Pathogenicity Test}
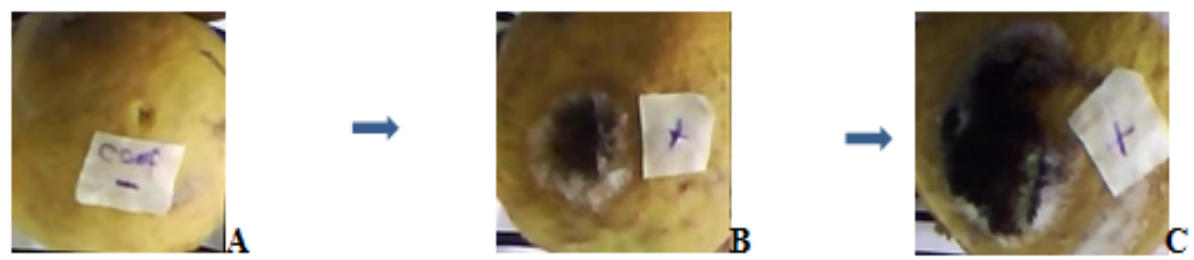

Pathogenicity Test (Koch's Postulates): A- Point of inoculation of fungal propagule; B- Initial growth of inoculated fungi; C- Well grown fungi.

*Carried out for all fungal isolates but data not shown due to space 


\section{Sample questionnaire}

INCIDENCE OF SOME FUNGAL STRAINS ON RIPPED, OVER-RIPPED AND SPOILT FRUITS IN LUGBE MARKET AND ITS POTENTIAL HEALTH IMPLICATIONS PROJECT QUESTIONNAIRE

1. Age: $<18 \square 19-45 \square>45$

2. Highest educational qualification:

3. Do you eat fruits? YES $\square$ NO If yes, why?

If No, why?

4. Do you know the difference between ripe and over-ripped fruit? YES

$\square$ NO

5. Do you eat over-ripped fruit? YES $\square$ NO $\square$

6. Are you aware of any danger in over ripped fruit? YES $\square$ NO $\square$

7. What do you think should be done to make people aware of the dangers associated with the consumption of such fruits? 